\title{
STUDIES IN EXPERIMENTAL ANEMIA
}

\section{An Immunologic Study of the Relation between Pernicious Anemia and Anemia Due to Welch Bacilius Toxin}

By ALVAN L. BARACH AND GEORGE DRAPER

With the Technical Assistance of Jacob Marcus

(From the Department of Medicine, Columbia University College of Physicians and Surgeons and the Presbyterian Hospital)

(Received for publication May 16, 1927)

In the first study (1) of this series chronic anemia was produced in rabbits by the injection of Welch bacillus toxin. The blood picture was characterized by (1) low color index, (2) anisocytosis without distortion of the shape of the cells, (3) rarity of nucleated red corpuscles. The histological examination of the organs showed changes consistent with blood destruction from any cause. Study of the spinal cord did not reveal the degenerative changes that are frequently found in pernicious anemia. The anemia which developed, however, was characterized by remissions when the injections were continued over long periods of time. The blood picture of rabbits which were given nonfatal doses returned to normal despite the continuance of injection of toxin. If large doses were then given the resistance could be broken down and anemia once more produced. This phenomenon could be repeated. It seemed theoretically possible that the remissions in pernicious anemia were due to a varying immunity on the part of the human organism to the Welsh bacillus toxin, and that furthermore, the protoplasm of the rabbit was not suited to produce the typical changes of pernicious anemia as they occur in man. For this reason it seemed important to determine the immunologic reactions associated with anemia due to Welch bacillus toxin and to compare them with those observed in pernicious anemia.

Agglutination of the Welch bacillus is specific for strain. Simonds (2) inoculated animals with the whole organism and observed agglutination up to 1 to 60 . Agglutination in higher dilution has been 
reported. The sera of five patients with pernicious anemia were tested with negative results. In three instances the strain derived from the stool of the patient was tested against the homologous serum. Old and fresh cultures were employed, and also organisms prepared by the method of Porges. The serum of rabbits made anemic by the injection of toxin, as was to be expected, also showed no agglutination.

The filtrates from the above cultures were tested against the sera of five pernicious anemia patients for precipitin reaction with negative results. The sera of rabbits suffering from chronic Welch bacillus anemia likewise gave no precipitin reaction with the filtrates used in producing the anemia.

A study of the anti-hemotoxin furnished a method for making a comparison between the clinical and experimental anemia. As shown by Bull and Pritchett (3), Welch bacillus toxin when mixed with serum containing anti-hemotoxin does not cause hemolysis in vivo. Lyall (4) developed a technique for measuring the hemolytic activity of the toxin in vitro and the titre of the anti-hemotoxic serum used. In this test varying amounts of toxin are incubated with 0.1 cc. serum for one hour at $37^{\circ} \mathrm{C}$., one cubic centimeter of a 5 per cent suspension of red blood cells is then added, and the mixture incubated for two additional hours. The absence of hemolysis indicates a protective amount of anti-hemotoxin present in the serum.

The toxin was prepared from veal broth made by the addition of $\frac{1}{2}$ pound of fresh veal to 1 liter of 0.2 per cent dextrose broth adjusted to a $\mathrm{pH}$ of 7.4. After 10 minutes boiling the $\mathrm{pH}$ was adjusted to 7.6 and the broth autoclaved for 15 minutes at 15 pounds pressure. The broth was inoculated with a Welch bacillus isolated from a normal stool and grown under vaseline for 18 hours. The culture was filtered through a Berkefeld " $\mathrm{N}$ " candle. One cubic centimeter of a 5 per cent suspension of rabbit's red blood cells were completely hemolyzed by $0.1 \mathrm{cc}$. of toxin.

\section{RESULTS}

The results of these tests have been tabulated under six headings: (1) normal human serum, (2) serum of patients with secondary anemia, (3) serum of patients with pernicious anemia, (4) normal rabbit serum, (5) serum of rabbits with acute anemia due to Welch bacillus 
TẢBLE 1

Inhibition of hemolytic activity of Welch bacillus toxin by the serum of nine normal individuals*

\begin{tabular}{|c|c|c|c|c|c|c|c|}
\hline \multirow{2}{*}{ Number } & \multicolumn{7}{|c|}{ Amount of toxin } \\
\hline & $0.025 \mathrm{cc}$. & $0.05 c c$ & $0.10 \mathrm{cc}$. & $0.20 \mathrm{cc}$. & $0.50 \mathrm{cc}$. & $0.50 \mathrm{cc}$. & $0.70 \mathrm{cc}$. \\
\hline 1 & - & + & $+t+$ & $++t$ & $+t+$ & $++t$ & $+t+$ \\
\hline 2 & - & - & $+t+$ & +++ & +++ & +++ & $t+t$ \\
\hline 3 & - & - & $++t$ & $++t$ & +++ & $++t$ & $+t+$ \\
\hline 4 & - & - & $+t+$ & $++t$ & +++ & +++ & $+t+$ \\
\hline 5 & - & - & $+t+$ & $++t$ & +++ & $+t+$ & $++t$ \\
\hline 6 & - & - & +++ & +++ & +++ & $++t$ & $++t$ \\
\hline 7 & - & - & $+t+$ & $++t$ & $++t$ & +++ & $++t$ \\
\hline 8 & - & - & $+t+$ & +++ & +++ & $+t+$ & $+t+$ \\
\hline 9 & - & - & $+t+$ & +++ & $++t$ & $+t+$ & $++t$ \\
\hline Control & - & - & +++ & $++t$ & +++ & $+t+$ & $+t+$ \\
\hline
\end{tabular}

* In this and subsequent tables $+++=$ complete hemolysis of a 5 per cent suspension of red blood cells.

TABLE 2

Inhibition of hemolytic activity of Welih bucillus toxin by serum of paticnts reith secondary anemia

\begin{tabular}{|c|c|c|c|c|c|c|c|}
\hline \multirow{2}{*}{ Number } & \multicolumn{7}{|c|}{ Amnunt of toxin } \\
\hline & $0.025 \mathrm{cc}$. & $0.05 \mathrm{cc}$. & $0.10 \mathrm{cc}$. & $0.20 \mathrm{cc}$. & $0.30 \mathrm{cc}$. & $0.50 \mathrm{cc}$ & $0.70 \mathrm{cc}$. \\
\hline 1 & - & + & +++ & +++ & $+t+$ & $+t+$ & $+t+$ \\
\hline 2 & - & - & +++ & $++t$ & $+t+$ & $+t+$ & $+t+$ \\
\hline Control & - & - & +++ & +++ & $+t+$ & +++ & $+t+$ \\
\hline
\end{tabular}

TABLE 3

Inhibition of hemolytic activity of Welch bacillus toxin by serum of eight patients with pernicious anemia

\begin{tabular}{c|c|c|c|c|c|c|c}
\hline & \multicolumn{7}{|c}{ Amount or toxin } \\
\cline { 2 - 6 } & $0.025 \mathrm{cc}$ & $0.05 \mathrm{cc}$ & $0.10 \mathrm{cc}$ & $0.20 \mathrm{cc}$ & $0.30 \mathrm{cc}$ & $0.50 \mathrm{cc.}$ & $0.70 \mathrm{cc.}$ \\
\hline 1 & - & - & ++ & +++ & +++ & +++ & +++ \\
2 & - & - & ++ & +++ & +++ & +++ & +++ \\
3 & - & - & ++ & +++ & +++ & +++ & +++ \\
4 & - & - & ++ & +++ & +++ & +++ & +++ \\
5 & - & - & ++ & +++ & +++ & +++ & +++ \\
6 & - & - & ++ & +++ & +++ & +++ & +++ \\
7 & - & - & ++ & +++ & +++ & +++ & +++ \\
8 & - & - & ++ & +++ & +++ & +++ & +++ \\
Control & & & ++ & +++ & +++ & +++ & +++ \\
\hline
\end{tabular}


toxin, (6) serum of rabbits with chronic anemia due to Welch bacillus toxin. The cases of pernicious anemia represented various stages of the disease from the severely anemic individual to one in remission.

TABLE 4

Inhibition of hemolytic activity of Welch bacillus toxin by serum of three normal rabbits

\begin{tabular}{|c|c|c|c|c|c|c|c|}
\hline \multirow{2}{*}{ Number } & \multicolumn{7}{|c|}{ Amount of toxin } \\
\hline & $0.025 \mathrm{cc}$. & $0.05 \mathrm{cc}$. & $0.10 \propto c$ & $0.20 \mathrm{cc}$ & $0.30 \mathrm{cc}$. & $0.50 \mathrm{cc}$. & $0.70 \mathrm{cc}$. \\
\hline 1 & + & ++ & +++ & $+t+$ & $+t+$ & +++ & $++t$ \\
\hline 2 & - & + & +++ & $++t$ & $++t$ & +++ & $+t+$ \\
\hline 3 & - & - & +++ & $++t$ & $+t+$ & +++ & +++ \\
\hline Control & - & + & +++ & $+t+$ & +++ & +++ & $++t$ \\
\hline
\end{tabular}

TABLE 5

Inhibition of hemolytic activity of Welch bacillus toxin by serum of rabbits in which chronic anemia was produced by Welch bacillus toxin

\begin{tabular}{l|c|c|c|c|c|c|c}
\hline \multirow{2}{*}{ Number } & \multicolumn{7}{|c}{ Amount of toxin } \\
\cline { 2 - 7 } & 0.025 cc. & 0.05 cc. & 0.10 cc. & $0.20 \mathrm{cc}$ & $0.30 \mathrm{cc.}$ & $0.50 \mathrm{cc}$ & $0.70 \mathrm{cc.}$ \\
\hline 1 & - & - & - & - & - & - & - \\
2 & - & - & - & - & - & - & - \\
3 & - & - & - & - & - & - & - \\
4 & - & - & - & - & - & - & - \\
5 & - & - & - & - & - & - & - \\
6 & - & - & - & - & - & - & - \\
7 & - & - & - & - & - & - & - \\
Control & - & - & +++ & +++ & +++ & +++ & +++ \\
\hline
\end{tabular}

TABLE 6

Inhibition of hemolytic activity of Welch bacillus toxin by serum of rabbits in which acute anemia was produced by Welch bacillus toxin

\begin{tabular}{c|c|c|c|c|c|c|c}
\hline & \multicolumn{8}{|c}{ Amount of toxin } \\
\cline { 2 - 6 } & $0.025 \mathrm{cc}$. & $0.05 \mathrm{cc}$. & $0.10 \mathrm{cc}$ & $0.20 \mathrm{cc}$ & $0.30 \mathrm{cc}$ & $0.50 \mathrm{cc.}$ & $0.70 \mathrm{cc.}$ \\
\hline 1 & - & - & +++ & +++ & +++ & +++ & +++ \\
2 & - & - & $\begin{array}{c}+ \\
+\end{array}$ & $\begin{array}{c}+ \\
+++\end{array}$ & +++ & +++ \\
3 & - & - & $\begin{array}{c}++ \\
+++\end{array}$ & +++ & +++ & +++ \\
Control & - & - & +++ & +++ & +++ & +++ & +++ \\
\hline
\end{tabular}


In tables 1, 2, 3, and 4 are recorded respectively the results in 9 normal individuals, 2 patients with severe secondary anemia, 8 patients with pernicious anemia and 3 normal rabbits. In no instance was there specific inhibition of hemolysis by any of the sera employed. However, the sera of 7 rabbits in which a chronic anemia was produced by the repeated injection of toxin gave complete inhibition of hemolysis (table 5). In four instances two tests were made, one at the time of maximum anemia and one in remission. The sera of 3 rabbits in which an acute anemia was produced by Welch bacillus toxin showed either no protection or little protection (table 6). No. 1 represented a rabbit in which severe blood destruction and death resulted in four hours as a result of the intravenous injection of Welch bacillus toxin. The serum gave no inhibition of hemolytic activity of toxin. In no. 3, the rabbit received two intravenous injections of toxin on successive days with a fall in red count from 7.0 million to 3.7 million, and of hemoglobin from 74 to 36 per cent. Blood taken on the second day showed no hemolytic activity. Rabbit no. 2 developed an anemia of the same severity as no. 3 in a period of three weeks from the intraperitoneal injection of toxin and at the end of that time his serum gave slight inhibition of hemolysis against 0.1 and $0.2 \mathrm{cc}$. of toxin but none against 0.3 to $0.7 \mathrm{cc}$. of toxin. Later, the blood count returned to normal and the serum gave complete protection against 0.1 to $0.7 \mathrm{cc}$. of toxin.

\section{SUMMARY}

Interpretation of this data brings out several facts of interest. The injection of Welch bacillus toxin into rabbits is followed by intravascular hemolysis which results in an anemia of varying degree depending on the amount and hemolytic titre of the toxin. In three weeks after the injection of toxin the rabbit's serum contains anti-hemotoxin. With the appearance of anti-hemotoxin the blood count begins to return to normal. Further injections of toxin are ineffective in maintaining the anemia. Once the rabbit has recovered from an anemia due to Welch bacillus toxin it shows for a period of approximately one year an increased resistance to the injection of toxin. The blood count remains normal with the persistence of anti-hemotoxin in the serum. Large doses of toxin, however, kept up for a long period 
will reinduce a severe anemia, even at a time when anti-hemotoxin is present in the blood. In this way a chronic anemia has been produced with periods of remission separating the individual attacks, characterized in both phases by the presence of anti-hemotoxin.

The sera of normal rabbits, normal individuals, patients with secondary anemia, and patients with pernicious anemia did not possess antihemolytic activity against Welch bacillus toxin. The series of pernicious anemia patients included instances of severe anemia as well as of remission. The absence of specific Welch bacillus anti-hemotoxin in the pernicious anemia patients studied and its uniform presence in chronic Welch bacillus anemia in the rabbit, suggests that these two anemias have a different etiologic mechanism.

\section{BIBLIOGRAPHY}

1. Draper, G., and Barach, A. L., J. Clin. Invest., 1927, iv, 507. Studies in Experimental Anemia. I. The Effects on Rabbits of the Injection of the Hemolytic Toxin of the Welch Bacillus.

2. Simonds, J. P., Mon. Rock. Institute, 1915, v. Studies in Bacillus welchii with Special Reference to Classification and to Its Relation to Diarrhea.

3. Bull, C. G., and Pritchett, I. W., J. Exp. Med., 1917, xxvi, 119. Toxin and Antitoxin of and Protective Inoculation against Bacillus welchii.

4. Lyall, H. W., J. Med. Res., 1914, xxx, 487. On the Classification of the Streptococci. 